\title{
Editorial
}

\section{Congresos de radiología 2019: propuestas y participación de la RAR}

\author{
Antonio da Rocha ${ }^{1,2}$ Alberto Surur ${ }^{3,4}$ \\ 1 Médico Neuroradiólogo, Dr. en Medicina, Santa Casa de Misericordia \\ de São Paulo, São Paulo, Brasil \\ 2 Departamento de Neurología y Neurocirugía de la Universidad \\ Federal de São Paulo, São Paulo, Brasil \\ 3 Médico Neuroradiólogo, Sanatorio Allende, Córdoba, Argentina \\ ${ }^{4}$ Profesor de Radiología en la Universidad Católica de Córdoba, \\ Córdoba, Argentina
}

Rev Argent Radiol 2019;83:139-140.

\section{Estimados lectores,}

Nos proponemos, en este editorial, hacer un pequeño recuento de las jornadas de radiología que compartimos en el transcurso de este año y que forman parte de la propuesta de congresos de América Latina.

En las Jornadas Paulistas de Radiología (JPR), que se celebran a principios del mes de mayo, se reúnen grandes celebridades de la radiología internacional, que brindan una excelente puesta al día de los avances en la radiología actual. Se trata de un congreso de alto nivel, celebrado en el enorme complejo Transamerica Expo Center, al que concurren unas 17.000 personas, incluyendo cerca de 8.000 médicos radiólogos de todo el mundo, siendo uno de los congresos de mayor convocatoria en el mundo de la radiología. Este año, este congreso integrado recibió maestros, residentes e directivos de sociedades médicas de la radiología de diversos países, muchos de ellos de Argentina, para conferencias en todas las áreas de nuestra especialidad.

La edición 2019 de JPR también sumó un programa específico para el intervencionismo (Jornada Paulista de Radiología Intervencionista), en sintonía con la actualidad, una oportunidad para el futuro de los médicos radiólogos. Estamos convencidos de que una sociedad no puede quedar aislada del mundo: tenemos que construir puentes, agregarnos, integrando nuestra membresía al universo de toda la especialidad.

Además, en 2019 se cumplió el último módulo de la European Course of Neuroradiology (ECNR), dentro del programa organizado por la European Society of Neuroradiology (ESNR). Este curso es organizado en conjunto por la Sociedad Paulista de Radiología (SPR) y la Asociación Colombiana de Radiología (ACR). Además del espíritu de integración e intercambio del conocimiento, este curso ofrece a toda la comunidad latinoamericana de neuroradiología una oportunidad única, con certificación y homogeneización para un nivel más elevado en la práctica de la especialidad. Se trata de

Address for correspondence Alberto Surur, Editor Responsible de la Revista Argentina de Radiología, Buenos Aires, Argentina

(e-mail: albertosurur@gmail.com). un gran beneficio para todos los médicos radiólogos con interés en la especialidad, pero aún más grande para nuestros pacientes, ya que nos ayuda a cumplir la misión primordial de nuestra profesión. Así, en algunos años, cada país de América Latina podrá contar con varios neuroradiólogos aprobados y certificados, reconocidos en distintos países de nuestro continente y en Europa, logrando que las puertas de la especialidad en el mundo estén abiertas para los talentos latinoamericanos. En el año 2020 São Paulo recibirá otra edición de las JPR, en conjunto con la Sociedad de Radiología de Norteamérica (RSNA, por su sigla en inglés), además de un nuevo programa con la ESNR, correspondiente a un curso para neuroradiología pediátrica.

Siguiendo nuestro recorrido, en el mes de junio se celebró el Congreso Internacional de Radiología en la ciudad de Córdoba, organizado por la Sociedad de Radiología y Diagnóstico por Imágenes de Córdoba (SORDIC). Este año, se celebró en conjunto con la Sociedad Latinoamericana de Radiología Pediátrica (SLARP). La convocatoria fue de 1.400 radiólogos, con temas como neuroradiología, radiología pediátrica, osteoarticular, radiología de la mujer, tórax y abdomen. Participaron, como conferencistas, médicos radiólogos internacionales de Estados Unidos, Francia, España, México, de toda América Latina, apoyados por profesores nacionales aportados por la Federación Argentina de Asociaciones de Radiología, Diagnóstico por Imágenes y Terapia Radiante (FAARDIT) y la Sociedad Argentina de Radiología (SAR), todos ellos de alto nivel académico. Se logró vincular a la Revista Argentina de Radiología (RAR) con el Dr. Da Rocha como Consultor Internacional en neuroradiología.

La RAR estuvo bien representada durante el congreso, con charlas informativas para revisores sobre el trabajo editorial y de revisión por pares, en las que participaron como oradores miembros del Comité Editorial como los Dres. Vasco Gálvez, Carolina Mariluis y Alberto Surur. Además, se seleccionaron
DOI https://doi.org/ 10.1055/s-0039-3402342. ISSN 1852-9992.
Copyright @ $\odot$ 2019, Sociedad Argentina de Radiología. Publicado por Thieme Revinter Publicações Ltda., Rio de Janeiro, Brazil. Todos los derechos reservados.
License terms

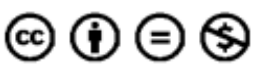


trabajos científicos que habían sido postulados a premios en el congreso para que sean sometidos a una revisión por pares y, de ser aceptados, se publiquen en nuestra revista.

Durante el mes de agosto, llegó el turno del Congreso Argentino de Diagnóstico por Imágenes (CADI), organizado por FAARDIT y SAR en la Ciudad Autónoma de Buenos Aires. Es de destacar la presencia de muchas empresas nacionales e internacionales, la enorme convocatoria, fundamentalmente de médicos nacionales y de América Latina, y el alto nivel de los oradores y de sus respectivas clases. Se ensambló además el congreso de la Sociedad Iberoamericana de Intervencionismo (SIDI) y el Simposio de la RSNA, cuyo tema fue "Imágenes de la Mujer".

Durante el congreso, se desarrolló el Taller para Revisores de la RAR, con charlas editoriales muy interesantes.
Los editores en jefe, Dres. Andrés Kohan y Alberto Surur, expusieron sobre el pasado y la actualidad de la RAR y su vinculación hacia América Latina, los revisores y su importante participación en la revista. La conferencia central fue "Razones para revisar para una revista biomédica y cómo hacerlo adecuadamente" por el Dr. José María García Santos, a través de teleconferencia desde España. Luego el Dr. Favio Mestas Núñez disertó sobre el "Reconocimiento a los revisores. Créditos CONAEDI" y, por último, se realizó la Entrega de diplomas a los mejores revisores de 2019.

En este editorial realizado en conjunto nos propusimos brindarles una información más detallada de algunos congresos y cursos relevantes de América Latina, sin dejar de mencionar la participación activa de la RAR en ellos. 